\title{
Self-Esteem And Emotional Intelligence Among Students In A Public Higher Learning Institution In Malaysia
}

\author{
Farhana Nabila Fakaruddin ${ }^{1,}$ Ida Hartina Ahmed Tharbe ${ }^{2}$ \\ 1,2 Department of Educational Psychology and Counselling, Faculty of Education, University of Malaya, Malaysia. \\ *E-mail: farhana5192@gmail.com
}

\begin{abstract}
This study was conducted to identify the relationship between self-esteem and emotional intelligence among students in a public higher learning institution in Kuala Lumpur. The respondents were 100 college students randomly selected from six faculties in the university. The instruments used for the study were Rosenberg Self-Esteem Scale (RSES) and Self Rated Malaysian Emotional Intelligence Scale (SRMEIS). The findings show that there were significant relationship between self-esteem and emotional intelligence among university students. Additionally, the data showed that self-esteem among university students in this study was at medium level while the level of emotional intelligence was high. The results can be used as reference by students, counselors, lecturers, university management, and for further research purpose.
\end{abstract}

Keywords: self-esteem; emotional intelligence; public higher learning institution

\section{Introduction}

In the effort to build a prosperous nation, the development of human capital and quality human resources cannot be overlooked and are closely intertwined. University graduates are among those who play the key role in leading the nation's leadership in the future. In fact, the credibility of university graduates depends on the extent of their positive self-development and mastery of soft skills in dealing with future challenges and problems.

During their college life, positive self-esteem and good emotional intelligence will help university students in their adaptation. In long run, they will also assist college students in coping with challenges in the real world. The Malaysia Youth Index (2015) indicates that self-esteem and emotional intelligence are among the important domains and indicators of significant selfdevelopment to produce a generation of eminent personalities. These two aspects also help the nation to produce mentally, physically and emotionally healthy youths who are capable of facing future challenges.

According to Sulaiman (2013), in this 21st century, there has been a social change, in which total success is not only measured through intellectual intelligence but also involves aspects of emotional intelligence. Students are often faced with various challenges, either academically or individually, that require self-esteem to deal with the problems that occur. Recent studies have also shown that positive self-esteem and good emotional intelligence among students have positive impact on the life of individuals. Rosenberg (in Yahaya \& Ahmad, 2006) stated that individuals with high self-esteem would respect and consider themselves as useful individuals. On the other hand, individuals with low self-esteem would not accept themselves well as they consider themselves to be useless and inadequate. According to McLeod (2008), based on Erik Erikson's approach, individual appreciation and uniqueness is an identity-building process. In addition, perfect personality development depends on the individual's freedom of choice. Regarding 
that, self-esteem also means self-assessment, consciousness, what the individual decides about self and how a person takes into account the decisions of others about himself (Muntoyo, 2007).

In terms of emotional intelligence, Mayer, Caruso and Salovey (1999) refer emotional intelligence to 'the ability to recognize the meanings of emotions and their relationships, and to reason and solve on the basis of them. Emotional intelligence is involved in the capacity to perceive emotions, assimilate emotion-related feelings, understand the information of those emotions, and manage them' (pp. 267). The abilities of emotional intelligence are essential for the development of positive personality and well-being of individuals. Mayer and Salovey (1997) explain that emotional intelligence is divided into four main processes. The four key processes in the model of emotional intelligence are identifying emotions, using emotions to facilitate the process of thinking, understanding emotions, and managing emotions. According to Buckley and Saarni (in Ciarrochi, Forgas \& Mayer, 2006), a person with developed emotional intelligence would be able to mobilize resources to learn new information, acquire new insights and develop his or her talents to full potentials.

Despite the findings on the importance of selfesteem and emotional intelligence, there is still a lack of studies about self-esteem and emotional intelligence among university students in Malaysia. In fact, many studies have been conducted only to examine the relationship between self-esteem and academic excellence. Some studies on emotional intelligence in Malaysia were - conducted among workers. Therefore, -this study aims to investigate the relationship between self-esteem and emotional intelligence among college students in Malaysia. In addition, this study would also examine the levels of self-esteem and emotional intelligence in Malaysian college students and the comparison of self-esteem and emotional intelligence based on gender.

\section{Literature Review}

Many researches has been conducted worldwide to assess the relevance of self-esteem and emotional intelligence towards the development of individuals. However, different results had been found. Kong, Zhao, and You (2012) studied on the role of selfesteem and social support for emotional intelligence and satisfaction of life among university students in China. The results showed self-esteem and social support mediated emotional intelligence and life satisfaction among students. They also found that male students tend to get higher life satisfaction than female students if they have high social support. Overall, their findings prove that selfesteem and emotional intelligence interrelates and contributes to student's satisfaction of life. Bibi and Saqlain (2016) study focused on emotional intelligence and self-esteem among university students in Pakistan. The result showed that there was a significant relationship between self-esteem and emotional intelligence. Their finding also showed that the level of emotional intelligence among female students was higher than male students.

On the other hand, study by Rahimi (2016) on the relationship among emotional intelligence, selfesteem, gender, and academic success in Iranian students had shown different result. Their study verified that there was no significant relationship between academic achievement with self-esteem and emotional intelligence among university students. Nevertheless, the level of self-esteem of female students was found to be higher than male students. In the discussion of this study, researcher also point out that psychological factors such as emotional intelligence and self-esteem cannot be a determining factor in solving the impact on academic achievement of students.

Focus on the effect of self-esteem, a study conducted by Samin (2016) tried to assess the relationship between self-esteem and depression among Bandar Penawar Community College students. Their study results supported that there was a significant negative relationship between selfesteem and depression among college students. Hence, this study proves that the high degree of self-esteem can help students achieve higher academic excellence. This study also proved that high level of self-esteem reduces the level of stress that may lead to depression among students.

Cazan and Nastasa (2015) conducted a study on emotional intelligence. They tried to verify whether emotional intelligence was associated with good adaptation and academic achievement among students. The results showed that there was a significant correlation between emotional intelligence with better adaptability and academic achievement in university. The findings also showed that the lack of satisfaction in the university led to an increase in the drop-out rate of students. In conclusion, this study demonstrates that high 
emotional intelligence can help college students in their adjustment in university.

\section{Methods}

Sample. This study involved students in a public university in Kuala Lumpur who are randomly selected from six faculties. Total of 100 students participated in the study, consisting of 52 female and 48 males.

Research Design. Quantitative survey method was used to gather the data needed for this study. Both descriptive and inferential statistical analysis of $t$-test and correlation were conducted in particular to answer the research question, using SPSS Version 23.

Based on those backgrounds, this study was guided by the research question, "Is there a significant relationship between self-esteem and EI in the undergraduates of a public university?". To provide a more comprehensive understanding of the study variables, this research also intended to answer these questions:

a) What is the level of self-esteem of undergraduate students in a public university?

b) What is the level of EI among undergraduates of a public university?

c) Is there a significant difference in the level of self-esteem between the male and female undergraduates of a public university?

Instrument and Measurement. Two instruments were used for the purpose of this study. Self-esteem was measured using the Rosenberg Self-Esteem Scale (RSES) by Morris Rosenberg (1965) which was previously translated into Malay language by Asmin (2010). This scale was proven to have good internal consistency $(\alpha=0.80)$. The RSES contains 10 items with 4-point Likert scale, ranging from $0=$ strongly agree to $4=$ strongly disagree for the positive items and vice versa for the negative items. Among the items, there are seven positive items and three negative items. The scores are interpreted as high (scores between 25 to 30), medium (scores between 15-25) and low (scores below 15).

Emotional intelligence was measured using the Self Rated Malaysian Emotional Intelligence scale/ SRMEIS (Ida \& Ng, 2017). The 39-items inventory measures the four domains of emotional intelligence based on Mayer and Salovey's (1997) emotional intelligence framework. The four domains are
Emotional Perception and Expression (EPE), Emotional Facilitation of Thinking (EFT), Emotional Understanding (EU) and Emotional Management (EM). For the purpose of this study, only the overall scores are taken into consideration on the basis of interpretation regardless of the scores of the four domains. The Cronbach's alpha for SRMEIS extracted during the pilot study of this research indicated a high internal consistency $(\alpha=$ 0.92). In this scale, participants are required to choose a response according to the 5-point Likert scale $(1=$ strongly disagree to $5=$ strongly agree $)$. The overall scores below 65 points indicate low EI, between $65-130$ points indicate medium EI, while scores above 130 indicate high EI.

Procedure. Both measurement scales were compiled as a questionnaire. The questionnaires were manually distributed and collected from participants at their respective faculties.

\section{Results}

Based on the descriptive data, the majority of participants $(60.0 \%)$ aged from 19 to 21 years old. The respondents consisted of $60 \%(\mathrm{~N}=60)$ Malay students, $6(6 \%)$ Chinese students and $7(7 \%)$ students from other ethnics backgrounds. By the faculty, participants of this study came from six different faculties, namely Faculty of Education (35\%), Engineering (20\%), Economics (12\%), Medicine and Science (13\%) and Law (7\%).

\section{Participants' Level of Self-Esteem and Emotional Intelligence}

Table 1 shows the level of self-esteem and emotional intelligence of participants in this study. As can be seen, this study found that students have medium level of self-esteem $(M=18.3)$. Along with that, their level of emotional intelligence (EI) can be categorized as high $(M=143.81)$. With reference to the four domains of EI, participants of this study also showed a high level of emotional perception and expression $(M=40.82)$, emotional facilitation of thinking $(M=51.75)$, and emotional management respectively $(M=39.96)$. Meanwhile, their level of emotional understanding was in medium level ( $M=11.28)$ These scores show that the students have high ability to perceive and express emotion accurately, use emotions to facilitate thought and manage their emotions. However, they have averaged in terms of the ability to understand emotions. 
Table 1

Level of self-esteem and emotional intelligence

\begin{tabular}{cccc}
\hline & Domains & Mean & Level \\
\hline Self Esteem & & 18.3 & Medium \\
& & & \\
\hline Overall EI & & 143.81 & High \\
& EPE & 40.82 & High \\
& EFT & 51.75 & High \\
& EU - & 11.28 & Medium \\
& EM & 39.96 & High \\
\hline
\end{tabular}

Note: EPE = Emotional Perception and Expression; EFT = Emotional Facilitation of Thinking; EU = Emotional Understanding; $\mathrm{EM}=$ Emotional Management

\section{Correlation between Self-Esteem and Emotional Intelligence}

Based on the result of Pearson Correlation Analysis between self-esteem and emotional intelligence, there was a significant positive relationship between self-esteem and emotional intelligence among university students $(r=0.522 ; p<.05)$.

\section{Comparison of Self-Esteem and Emotional Intelligence between Gender}

Table 1.2 illustrates the results of independent sample $t$-test analysis to compare the level of selfesteem and emotional intelligence between male and female students. It reveals significant difference $(t(100)=2.67, p<.05)$ between the self-esteem score of male students $(\mathrm{M}=17.31, S D=3.78)$ and female students $(\mathrm{M}=19.21, S D=3.33)$, with female students having higher level of self-esteem. These results also show significant difference $(t(100)=$ $2.38, p<.05)$ on the overall EI scores between male $(M=140.32, S D 12.63)$ and female $(M=147.03, S D$ $=15.41)$ students. This finding indicates that female students have higher emotional intelligence.

Table 1.2

t-test Results of Self-esteem and Emotional Intelligence based on Gender

\begin{tabular}{lccc}
\hline & Variable & Self-Esteem & EI \\
\hline Male & $M$ & 17.31 & 140.31 \\
& $S D$ & 3.78 & 12.63 \\
Female & $M$ & 19.21 & 147.03 \\
& $S D$ & 3.33 & 15.41 \\
$t$ & & 2.67 & 2.376 \\
$p$ & & $0.009^{*}$ & $0.019^{*}$ \\
\hline${ }^{*} \mathrm{p}<.05$ & & &
\end{tabular}

\section{Discussion \& Conclusion}

This study has verified the hypothesis about the relationship between self-esteem and emotional intelligence (EI). This result is consistent with the finding of Schutte et al (2002), which found that higher emotional intelligence enables individuals to maintain higher level of self-esteem, thus having better perception of self-worth or value. Salovey et al (2002) found that mood clarity and mood repair are positively correlated with self-esteem. Therefore the understanding of the relationship between selfesteem and emotional intelligence is very important in the effort to assist university students in coping with challenges of university life and beyond. The significant relationship found between self-esteem and emotional intelligence among students provides a useful basis for further research and interventions. Counselors may provide training as interventions to improve self-esteem to enhance EI or vice versa in line with this objective. Further research are also recommended to determine the direction of the relationship whether self-esteem influence emotional intelligence or the other way round.

Previous studies have found inconsistency in their finding of self-esteem level among university students. However, this study's findings show that the level of self-esteem among Malaysian university students is at a medium level. This result supports the finding of Othman (2006) which found that the level of self-esteem among university students was at moderate level. This study also revealed consistent result with the study of Kosnin et al. (2003) that also reported that the level of selfesteem of university students was at moderate level. Self-esteem among students depends on how they judge themselves in various aspects of life. Level of self-esteem can be influenced by their ability to cope and adapt to challenges in university life. Problem they face in adapting to the university environment and lifestyle will indirectly affect the level of their self-confidence and self-esteem (Kosnin 2013). It could explain why the self-esteem level of students in this study was medium instead of high.

Overall, the students in this study have high level of emotional intelligence (EI). This finding is similar to the findings by Che Ani (2013) and Cazan and Nastasa (2015). This implies that they are good at perceiving and expressing their emotion, know how to use their emotions in making rational decisions and have the ability to manage their emotions well. Although they score moderately in terms of emotional understanding, all the domains of EI can be enhanced and further developed through proper training. Chan (2005) believes that individuals might benefit from special guidance and counseling services, training and support to enhance their EI. 
Being emotionally intelligence can be a great advantage to these students in their future development, personally and professionally. Personally, individuals with high EI have been said to be able to intuitively understand what others need, aware of their own strength and weaknesses, able to remain 'unruffled' by stress and tend to connect better with other individuals (Stein \& Book, 2000). Professionally, many researchers argued that there is a direct link between EI and job performance (Kluemper, DeGroot and Choi; 2013) and plays an important role in leadership behaviors (Boyatzis, Good \& Massa; 2012).

The findings show that the level of self-esteem among male students is lower than female students. This finding is consistent with the study conducted by Rahimi (2016), who found that the level of selfesteem among female students was higher than male students. This is probably because men are a minority group in the university setting, compared to women. Thus, this situation could impose a sense of challenge to them. Therefore, male students may need to be more acquainted with the situation in order to be more proactive and improve their competitiveness. Kong et al. (2012) suggested that the level of self-esteem among male students can be enhanced through positive social support from others.

Similar condition found for emotional intelligence. Female students were measured to have higher level of emotional intelligence compare to their male counterparts. This finding supported the earlier studies by Bibi, Saqlain \& Musawwar (2016) and Walsh and Joyce (2011). Several studies argued that women tend to be more emotionally intelligent because they received education biased towards emotions while men are taught to minimize certain emotions related to sadness, guilt, vulnerability and fear (Brody \& Hall, 1999; Sánchez, FernándezBerrocal, Montañés, \& Latorre, 2008). Studies also conclude that women have a greater emotional knowledge and tend to they express their emotions more fluently and more frequently and can easily adapt themselves socially compared to men. (Brody \& Hall, 2000; Ciarrochi, Hynes, \& Crittenden, 2005; Hall \& Mast, 2008) Acceptance and social support received by female students at the university also affects the high level of emotional intelligence.

\section{References}

Bibi S, Saqlain S, Mussawar B (2016) Relationship between Emotional Intelligence and Self Esteem among
Pakistani University Students. Journal of Psychology and Psychotherapy 6:279. doi:10.4172/21610487.1000279

Boyatzis, R.E., Good, D. \& Massa, R. 2012. Emotional, social, and cognitive intelligence and personality as predictors of sales leadership performance. Journal of Leadership and Organizational Studies 19: 191-201.

Brody, L. R., \& Hall, J. A. (2000). Gender, emotion, and expression. In M. Lewis, \& J. M. Haviland (Eds.), Handbook of emotions (pp. 338-349). New York: Guilford.

Buckley, M., \& Saarni, C. 2006. Skills of emotional competence: Developmental implications. In J. Ciarrochi, J. P. Forgas \& J. D. Mayer (Eds.), Emotional Intelligence in Everyday Life (2nd ed., pp. 51-76). New York: Psychology Press.

Cazan, A. \& Nastasa, L. (2015). Emotional Intelligence, Satisfaction with Life and Burnout among University Students. Procedia - Social and Behavioral Sciences, 180, $1574-1578$.

Che Ani, R. (2013). Kecerdasan Emosi dalam Kalangan Pelajar Diploma Pendidikan Lepasan Ijazah (DPLI). Universiti Tun Hussein Onn Malaysia - UTHM Institutional Repository. Eprints.uthm.edu.my.

Ciarrochi, J. V., Hynes, K., \& Crittenden, N. (2005). Can men do better if they try harder? Sex and motivational effects on emotional awareness. Cognition and Emotion, 19, 133-141.

Hall, J. A., \& Mast, M. S. (2008). Are women always more interpersonally sensitive than men? Impact of goals and content domain. Personality and Social Psychology Bulletin, 34, 144-155.

Ida Hartina Ahmed Tharbe \& Ng, K.M. (2017). Development of Self Rated Malaysian Emotional Intelligence Scale. MOJC: Malaysian Online Journal of Counseling, 4(1), 24-36.

Kluemper, D.H., DeGroot, T. \& Choi, S. 2013. Emotion management ability predicting task performance, citizenship, and deviance. Journal of Management. 39(4): 878-905

Kong, F., Zhao, J., \& You, X. (2012). Emotional intelligence and life satisfaction in Chinese University Students: The Mediating Role of Self-Esteem and Social Support. Personality and Individual Differences, 53(8), 1039-1043.

Kosnin, M., Azlina. S., Rajab, S., Wan Zakaria, A., Wan Zarina. (2003). Pengaruh Amalan Keibubapaan Terhadap Penghargaan Kendiri Pelajar Peringkat Awal Dewasa. Jurnal Kemanusiaan, 17 (2). 1-11. Universiti Teknologi Malaysia.

Mayer, J. D., \& Salovey, P. (1997). What Is Emotional Intelligence? In P. Salovey \& D.J. Slyuter (Eds.), Emotional Development and Emotional Intelligence: Educational Implications (pp.3-34). New York: Harper Collins.

Mayer, J.D., Caruso, D.R., \& Salovey, P. (1999). Emotional Intelligence meets traditional standards for an intelligence. Intelligence, 27, 267-298

McLeod, S. (2008). Erikson's Psychosocial Stages of Development. Simply Psychology.

Muntoyo. (2007). Sokongan Keluarga dan Penghargaan Kendiri di Kalangan Murid Cemerlang di Sebuah Sekolah Menengah di Kuala Lumpur. Perpustakaan Universiti Malaya.

Othman, N. (2006). Hubungan Antara Harga Diri dan Pencapaian Akademik Pelajar Pelajar Tahun Lima Kursus Sains dan Matematik. Tesis yang tidak 
diterbitkan. Fakulti Pendidikan Universiti Teknologi Malaysia.

Rahimi, M. (2016). The Relationship between Emotional Intelligence, Self-Esteem, Gender and Educational Success. Management Science Letters, 481-486.

Salovey, P., Mayer J.D., \& Caruso, D. 2002. The positive psychology of emotional intelligence. In Snyder, C.R \& Lopez, S.J. (Eds). Handbook of positive psychology, pp 159-171. New York: Oxford University Press Inc

Samin, Z. (2016). Hubungan Penghargaan Kendiri dan Kemurungan dalam Kalangan Pelajar Kolej Komuniti Bandar Penawar Johor. Kolej Komuniti Bandar Penawar Johor.

Sánchez Núñez, M. T., Fernández-Berrocal, P., Montañés, J., \& Latorre, J. M. (2008). Does emotional intelligence depend on gender? The socialization of emotional competencies in men and women and its implications.
Electronic Journal of Research in Educational Psychology, 15, 455-474.

Schutte, N.S., Malouff, J.M., Simunek, M., Mckenley, J. \& Hollander, S. 2002. Characteristic emotional intelligence and emotional well-being. Cognition and Emotion 16(6): 769-785.

Sulaiman, H. (2013). Hubungan Antara Kecerdasan Emosi dengan Gaya Asuhan Ibu Bapa dalam Kalangan Remaja Sekolah. Tesis yang tidak diterbitkan. Universiti Malaya.

Walsh-Portillo \& Joyce, G. (2011). The Role of Emotional Intelligence in College Students'Success. FIU Electronic Theses and Dissertations. 491.

Yahaya, A. \& Ahmad, N. (2006). Teori-Teori Konsep Kendiri. Universiti Teknologi Malaysia, Malaysia. http://eprints.utm.my/10368/3/Norlaily_Binti_Ahmad .pdf 